\title{
Gold Nanoparticles and Nanocomposites in Clinical Diagnostics Using Electrochemical Methods
}

\author{
Pranjal Chandra, ${ }^{1,2,3}$ Jai Singh, ${ }^{4}$ Amardeep Singh, ${ }^{2}$ Ananya Srivastava, \\ Rajendra N. Goyal, ${ }^{3,6}$ and Yoon Bo Shim ${ }^{2,3}$ \\ ${ }^{1}$ Amity Institute of Biotechnology, Amity University Uttar Pradesh, Sector 125, Noida 201303, India \\ ${ }^{2}$ Department of Chemistry, Pusan National University, Busan 609-735, Republic of Korea \\ ${ }^{3}$ Institute of BioPhysio Sensor Technology, Pusan National University, Busan 609-735, Republic of Korea \\ ${ }^{4}$ Faculty of Nanotechnology and Advanced Materials, HMC, and Graphene Research Institute, Sejong University, \\ Seoul 143-747, Republic of Korea \\ ${ }^{5}$ Department of Chemistry, DDU Gorakhpur University, Gorakhpur 273009, India \\ ${ }^{6}$ Department of Chemistry, Indian Institute of Technology Roorkee, Roorkee 247667, India
}

Correspondence should be addressed to Pranjal Chandra; pchandral@amity.edu and Yoon Bo Shim; ybshim@pusan.ac.kr

Received 30 November 2012; Accepted 5 February 2013

Academic Editor: Young-Seok Shon

Copyright (C) 2013 Pranjal Chandra et al. This is an open access article distributed under the Creative Commons Attribution License, which permits unrestricted use, distribution, and reproduction in any medium, provided the original work is properly cited.

Progress and development in clinical diagnostics certainly focus upon the advances in the nanomaterials, particularly gold nanoparticles (AuNPs) that offer promise to solve the biocompatible and sensitive detection systems. This paper focuses on the recent application of AuNPs in clinical diagnosis. Various important methods of AuNPs synthesis and their application in clinical detection of various biomolecules using electrochemical detection methods have been described. AuNPs alone and in various composites are also described based on the various biosensors design recently published for the detection of cancer biomarkers, proteins, bacteria, and cancer cells. The effect of AuNPs type and size in clinical detection has also been briefly illustrated.

\section{Introduction}

The last decade has witnessed an exponential progress of activities in the field of nanoscience and nanotechnology worldwide, motivated both by the anticipation of considerate new science and by the impending trust for applications and financially feasible impacts. The prime action in this field has been in the production and characterization of new materials consisting of particles with dimensions in the order of a few nanometers, purported nanocrystalline materials. These nanosized materials have properties that are often significantly different from their counterparts with the bulk size $[1,2]$.

Inorganic, organic, and biological nanomaterials may have existed in nature since the evolution of life started on earth [3]. Some evident examples are microorganism and fine grained minerals in rocks [4]. In addition, nanostructures include quantum dots, quantum wires, grains, particles, nanotubes, nanorods, nanofibers, nanofoams, nanocrystals, nanoprecision self-assemblies, and thin films of metals, intermetallics, semiconductors, ferroelectrics, dielectrics, composites, alloys, blends, organics, organominerals, biomaterials, biomolecules, oligomers, polymers, functional structures and devices [5-8]. These novel materials made up of nanosized grains or building blocks offer unique and entirely different electrical, optical, mechanical, and magnetic properties compared to conventional micro- or millimetersize materials owing to their distinctive size, shape, surface chemistry, and topology $[7,8]$. Nanostructured materials and their base technologies have opened new exciting possibilities for future applications in medical, aerospace, catalysts, batteries, nonvolatile memories, sensors, insulators, color imaging, 
printing, flat panel displays, waveguides, modulators, computer chips, magneto-optical discs, transducers, photodetectors, optoelectronics, solar cells, lithography, holography, photoemitters, molecular sized transistors and switches, drug delivery, medicine, medical implants, pharmacy, cosmetics, and several others [9-12].

In general, noble metal used in the field of nanobiotechnology range in particle size between 10 and $100 \mathrm{~nm}$, rarely exceeding above than $600 \mathrm{~nm}$ [13]. Biocompatible metal nanoparticles have gained considerable attention in recent years for potential applications in nanomedicine due to their interesting size dependent chemical, electronic, and optical properties [14]. In addition, silver (Ag) and gold (Au) nanoparticles (NPs) have fascinated scientist for over a century and are now heavily utilized in biomedical sciences and engineering [15-17]. The nanosize of these particles allows various messages with biomolecules on the cell surfaces and within the cells in way that can be decoded and designated to various biochemical and physiochemical properties of these cells [18]. Similarly, its potential application in drug delivery and noninvasive imaging offered various advantages over conventional pharmaceutical agents. In an effort to utilize nanoparticles at their full choke, it is important that the nanoparticulate systems should be stable, biocompatible, and selectively directed to specific sites in the body after systemic administration [19]. More specific targeting systems are designed to recognize the targeted cells such as cancer cells. AuNPs have attracted huge scientific and technological interest due to their ease of synthesis, chemical stability, and unique properties. The applications of AuNPs in different field are summarized in Table 1.

\section{Synthetic Routes for the Preparation of AuNPs}

Inorganic nanomaterials have received remarkable attention in the past few years due to their optical and well-defined size related to electronic properties [29-31]. Development of new materials in the nanometer scale called nanoparticles (NPs) is expected to form the basis of many of the technological and biological innovations of this century [32-35]. Particularly, AuNPs are being considered in chemistry, biological, and medical due to their oxide-free surface, bioconjugation properties, good biocompatibility, and unique optical properties. Specifically, because of optical activity, AuNPs are extensively used in colorimetric biosensors [36, 37], drug delivery [38-40], cancer imaging [41-44], and cancer therapies [45, 46]. They also have the potential to help establish specific beneficial processes and achieve selectivity within biological settings. These applications have sparked great interest in the development of synthetic methods for preparing different gold-based nanostructures. The general synthesis methods of AuNPs are briefly described in this section.

2.1. General Synthetic Routes. AuNPs can be manufactured into a variety of shapes including Au nanospheres, nanorods, nanoshells, nanocubes, nanoclusters, and nanostars [46-48]. The development of simple and versatile methods for the preparation of NPs in a size- or shape-selected and controlled manner has been a challenging but intellectually rewarding task (Figure 2). Most commonly, a $\mathrm{Au}$ (III) salt is reduced to $\mathrm{Au}(0)$ to form an activated species, either in a single step or via a $\mathrm{Au}(\mathrm{I})$ intermediate followed by reduction to $\mathrm{Au}(0)$. These activated $\mathrm{Au}(0)$ species are thermodynamically unstable and rapidly aggregate to form nuclei and eventually the desired gold nanoparticle, as presented in Figure 1.

This is typically achieved not only by altering the relative growth rates of different facets by the selective localization of surface-modifying or capping agents, but also by the modulation of nucleation and reaction parameters such as time, temperature, reagent concentration, and $\mathrm{pH}$ [49-52]. On the basis of reported literature, [46-68] the following methods have been widely used in the synthesis of nanoparticles.

2.2. Physical Methods. Many of the physical methods have been involved to the synthesis of Au nanoparticles [53-55]. In these methods, the size of the NP is controlled by temporarily inactivating the source of evaporation or by slowing the rate by introducing gas molecules to collide with the particles. The growth of nanoparticles generally occurs rapidly, from milliseconds to seconds, requiring precise control over experimental parameters.

2.2.1. Photochemistry (UV, Near-IR), Sonochemistry, and Radiolysis. Photochemical synthesis of nanoparticles is carried out by the light-induced decomposition or the reduction of a metal salt by photogenerated reducing agents such as solvated electrons (radiolysis). UV-irradiation is another method that can improve the quality of the AuNPs especially when it is used in synergy with micelles or seeds [55]. NearIR laser irradiation facilitates an enormous size growth of thiol-stabilized AuNPs [56]. Sonochemistry can also be used for the synthesis of AuNPs within the pores of silica [57]. Radiolysis has been used to control the AuNPs size or to synthesize them in the presence of specific radicals [58], and the mechanism of AuNPs formation upon $\gamma$-irradiation has been carefully examined [59]. Laser photolysis has been used to produce AuNPs in block copolymer micelles [60]. Laser ablation is another technique for AuNPs synthesis that has been used under various conditions, whereby size control can be induced by a laser.

2.3. Chemical Methods. Chemical methods have emerged to be indispensable for synthesizing nanocrystals of various types of materials. These methods are generally carried out under mild conditions and are relatively straightforward. One of the important factors that determine the quality of a synthetic procedure is the monodispersity of the nanocrystals obtained. It is desirable to have nanoparticles of nearly the same size, in order to be able to relate the size and the property under study. A variety of reducing agents, such as sodium borohydride, presence of sodium hydroxide, ascorbic acid, sodium citrate, trisodium citrate, and hydrogen peroxide have been used in the reduction of $\mathrm{Au}(\mathrm{III})$ ions to $\mathrm{Au}(0)$ [61-63]. Such reduction takes place in the presence of one or more water-soluble polymers, surfactants, or capping agents 
TABLE 1: Expected applications of AuNPs in various areas.

\begin{tabular}{|c|c|c|}
\hline $\begin{array}{l}\text { Serial } \\
\text { number }\end{array}$ & Fields & Applications \\
\hline 1 & Electronics & $\begin{array}{l}\text { AuNPs are considered for use as conductors from printable inks to electronic chips. As the } \\
\text { world of electronics becomes smaller in size, nanoparticles are important components in the } \\
\text { electronic chip design. AuNPs are being used to connect resistors, conductors, and other } \\
\text { elements of electronic devices [20]. }\end{array}$ \\
\hline 2 & Photodynamic therapy & $\begin{array}{l}\text { Photodynamic therapy that is a mode of treatment by laser light at a particular wavelength is } \\
\text { combined with exogenous chromophores to accomplish a therapeutic effect. Near-IR } \\
\text { absorbing AuNPs (including Au nanoshells and nanorods) produce heat when excited by } \\
\text { light at wavelengths from } 700 \text { to } 800 \mathrm{~nm} \text {. This enables these nanoparticles to destroy } \\
\text { targeted tumors. When light is applied to a tumor-containing AuNPs, the particles rapidly } \\
\text { heat up, killing tumor cells in a treatment also known as hyperthermia therapy [21]. }\end{array}$ \\
\hline 3 & Therapeutic agent delivery & $\begin{array}{l}\text { Therapeutic agents can be covered with AuNPs. Whereas the NIR-resonant Au/silica } \\
\text { nanoshells used in therapeutic and imaging applications have an average diameter of } \\
120-140 \mathrm{~nm}[22] .\end{array}$ \\
\hline 4 & Sensors & $\begin{array}{l}\text { AuNPs can be used in different sensors. For example, a colorimetric sensor based on AuNPs } \\
\text { can identify if foods are suitable for consumption [23]. Other methods, such as } \\
\text { surface-enhanced Raman spectroscopy, exploit AuNPs as substrates to enable the } \\
\text { measurement of vibrational energies of chemical bonds. This strategy could also be used for } \\
\text { the detection of proteins, pollutants, and other molecules label-free [24]. }\end{array}$ \\
\hline 5 & Probes & $\begin{array}{l}\text { AuNPs also scatter light and can create an array of interesting colors under dark-field } \\
\text { microscopy. The scattered colors of AuNPs are currently used for biological imaging. Also, } \\
\text { AuNPs are relatively dense, allowing them helpful as probes for transmission electron } \\
\text { microscopy [25]. }\end{array}$ \\
\hline 6 & Diagnostics & $\begin{array}{l}\text { AuNPs are also used to detect biomarkers in clinical and medical diagnosis. They are also } \\
\text { useful in the lateral flow immunoassays, a common household example being the home } \\
\text { pregnancy test [26]. }\end{array}$ \\
\hline 7 & Catalysis & $\begin{array}{l}\text { AuNPs are used as catalysts in a number of chemical reactions [27]. The surface of AuNPs } \\
\text { can be used for oxidation or reduction of certain chemicals. AuNPs are being developed for } \\
\text { fuel cell applications. These technologies would be useful in the automotive and display } \\
\text { industry. }\end{array}$ \\
\hline 8 & Fluorescence properties & $\begin{array}{l}\text { Fluorescence-based detection techniques are among the most highly sensitive and popular } \\
\text { biological tests in the clinical analysis. AuNPs show outstanding behavior of antiphoto } \\
\text { bleaching under the presence of powerful light [28]. }\end{array}$ \\
\hline
\end{tabular}

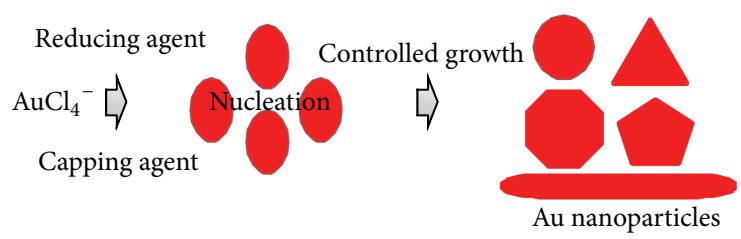

FIGURE 1: Synthetic route of growth of gold nanoparticles.

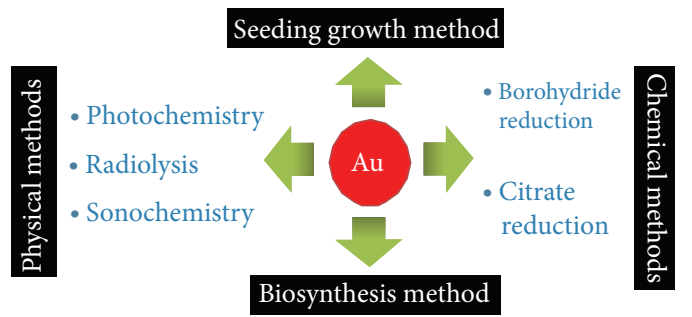

FIGURE 2: Various methods for AuNPs preparation. 
and with introducing external supplied energy such as photo irradiation, ultrasound irradiation, or heating. These methods allow for adequate control of the size and concentration of the dispersed particles. Moreover, the surface-modifying or capping agents help to make colloidal stabilization and prevent NPs aggregation [62]. The most common approach to achieve colloidal stability proceeds via chemical binding of ligands at the surface of the NPs and a covalent linkage between the ligand. It may change the properties of the NPs through a modification of their electronic density and the dielectric constant of the surrounding medium. A strategy based on the physical adsorption of ligands on the surface of the nanoparticles may be preferable, in order to maintain the intended properties of the nanomaterials. The two reduction methods are outlined as follows.

2.3.1. Borohydride Reduction. The preparation of metal NPs in solution is most commonly based on the chemical reduction of metallic ions to be metalized in organic/aqueous solvent. The reduction by borohydride has been in existence for a number of years $[64,65]$. Although, various metal nanocrystals have been synthesized via the borohydride reduction method, but this method is widely used in the synthesis of AuNPs. Superhydride and hexadecylaniline have been used as alternative reagents to $\mathrm{NaBH}_{4}$ for the reduction of $\mathrm{Au}(\mathrm{III})$ in the synthesis of thiol-stabilized AuNPs [66]. Problems associated with borohydride reduction include its irreproducibility, especially in the aqueous medium and the incorporation of boron in the product [67].

2.3.2. Citrate Reduction. The most common method of synthesizing gold nanoparticles is through the use of citrate. Jana et al. reported that adding sodium citrate to a boiling solution of chlorauric acid led to the formation of gold nanoparticles [68]. Later work showed that variations in temperature and the ratio of reactants allowed for control over the core size from 10 to $100 \mathrm{~nm}$ [69]. More recent work has shown that $\mathrm{Au} /$ citrate solutions reduced with $\mathrm{NaBH}_{4}$ allow the synthesis of nanoparticles $<10 \mathrm{~nm}$ in average core size. Despite being the most common method of producing gold nanoparticles, citrate-stabilized nanoparticles are disadvantageous for several reasons. First, they cannot be isolated from solution, making it difficult to store or study them in the solid state. Second, their stability with changes in $\mathrm{pH}$ or ionic strength is minimal. Finally, and most importantly, their functionalization, either through ligand exchange derivatization of carboxylic acids in the ligand shell, is extremely limited.

2.4. Seeding-Growth Method. The seeding-growth procedure is another popular technique that has been used for a number of years. Recent studies have successfully led to control of the size distribution in the range $5-40 \mathrm{~nm}$, whereas the sizes can be manipulated by varying the ratio of seed to metal salt [70]. The step-by-step particle enlargement is more effective than a one-step-seeding method to avoid secondary nucleation. Gold nanorods have been conveniently fabricated using the seeding-growth method [71]. In a typical seeded growth reaction, a previously synthesized "seed" nanoparticle is introduced to a growth solution containing an $\mathrm{Au}$ (III) salt, a weak reducing agent, and a directing agent (most commonly a surfactant). Initially, the seed particles grow through the slow diffusion of gold atoms onto their surface.

2.5. Biosynthesis Methods. As far as the synthesis of nanoparticles is concerned there is a great and growing need to develop clean, nontoxic, and environmentally friendly synthetic procedures. Biological methods have recently been considered as possible environmentally friendly nanofactories. Both living and dead microorganisms are gaining importance by virtue of their facile assembly of nanoparticles. Prokaryotic bacteria have primarily attracted the most attention in the area of biosynthesis of metal nanoparticles [72]. Different research groups continued to accomplish some excellent work based on uni- and multicellular organisms, Algae, and Fungi to synthesize inorganic materials, both intra- and extracellularly. However, the use of plants and their extracts for NP synthesis is a comparatively new and underresearched technique. The majority of research on the use of plants to synthesize AuNPs has been investigated without the need for their removal from the plant biomatrix [73]. More recently synthesized mesoporous material SBA-16 are used synthesis of AuNPs for preventing the aggregation or growth of metal NPs [74].

2.6. Overview of Synthesized AuNPs. Despite the progress achieved, concerns, and problems with the preparation of metal NPs remain, such as the byproducts from the reducing agent, the multiple steps often required, and the high concentration of protective agents. In addition, a simple modification of the surface functionalization of the citratestabilized AuNPs with a variety of chemical and biochemical vectors is also another important factor to be considered. The ability to synthesize smaller AuNPs while preserving their biocompatibility and derivability would present new alternatives for these areas of research. To date, isotopic replacement of the solvent has solely been explored in the case of Au nanorods seeding-growth. Finally, the modification of the reducing and reduced species due to isotope replacement offers unique insights into the AuNP formation mechanism [75]. Recently, AuNPs are synthesized using monosodium glutamate as a reducing agent. However, the particles possess the tendency to aggregate in high molar ratios of gold capped with glutamates and are therefore unstable. Consequently, PMMA is introduced as a polymer-capping agent to stabilize the AuNPs [76]. Thus, nature of the particle stabilizer, solvent, reaction condition, namely, $\mathrm{pH}$, temperature, and so forth, plays crucial role in determining the final size of the particles. It is also important to note that the citrate/aqueous synthesis of AuNPs is the most employed recipe in today nanotechnology explosion. All these novel procedures offer an attractive alternative to the existing ones and open a full range of possibilities for biological studies. 


\section{Nanosensors Based on Nano-AuNPs in Clinical Chemistry}

AuNPs are one of the highly used particles in sensors used for clinical chemistry. In this section, the detection of some important clinical molecules has been summarized using AuNPs or AuNPs-composite sensor. A review on the use of AuNPs and AgNPs for clinical diagnosis has also appeared in the literature [77]. It has been demonstrated that the use of nanoparticles not only improves the performance of sensors but also permits arrays of sensors to be constructed for parallel sensing [78]. The chemical methods have also been found to produce AuNPs of different shapes such as spherical, nanoplates, and flower shapes [79, 80]. A comparison of spherical AuNPs and nanogold plates-based indium tin oxide (ITO) sensor has been reported for the determination of dopamine and ascorbic acid [81]. The nanoplates based sensor has been found to exhibit higher electrocatalytic activity for both compounds due to their (1 111 ) lattice as the basal plane and due to more available surface edges. In addition the increased surface area of nanoplates, due to their large dimension (400-500 nm), also appears to play a significant role. A review on the biopharmaceutical applications of AuNPs has also appeared in the literature describing the detection of diseases biomarker for the diagnosis of patients with germ cell tumors and hepatocellular carcinoma [82]. The biosensing and therapeutic applications of AuNPs have been found due to their catalytic properties. An electrochemical immunoassay method has also been reported for the detection of tumor markers based on electrochemical stripping of AuNPs, which were deposited by immunosensor array with a reduction reaction catalyzed by AuNPs [83]. The method was sensitive, and a detection limit of $3.5 \mathrm{pg} / \mathrm{mL}$ was observed with acceptable reproducibility. Significant methods for the determination of brain neurotransmitters have been developed in the past few years using AuNPs. One commonly known neurotransmitter is dopamine (DA), chemically known as 4-(2-aminoethyl) benzene-1,2-diol, widely present in the mammalian brain tissues and plays a pivotal role in the function of the cardiovascular, hormonal, renal, and central nervous systems. Abnormal levels of DA have been linked with Parkinson's disease, Tourette's syndrome, Schizophrenia, attention deficit hyperactive disorder, and generation of pituitary tumours. Similarly, serotonin (5-hydroxytryptamine or 5 -HT) is a monoamine neurotransmitter widely distributed in the brain tissues and plays a significant role in temperature regulation, muscle contraction, liver regeneration, endocrine regulation, depression, and so forth. It has also been found that DA and 5-HT influence each other in their respective releasing, and hence simultaneous determination of DA and 5-HT has been carried out using AuNPs-based nanosensors. These nanosensors have been found rapid and convenient for the simultaneous determination of DA and 5-HT in human serum and urine with detection limit of 0.5 and $3.0 \mathrm{nM}$, respectively [84]. The large excess of ascorbic acid (AA) in biological fluids did not interfere in the determination. Norepinephrine (NE) is also a significant neurotransmitter present in many parts of the central nervous system, where it is engrossed in emotional arousal, blood pressure regulation, and mood disorders. The determination of NE in biological fluids has also been carried out at AuNPs nanosensor using square wave voltammetry. A stable layer of AuNPs was deposited on the surface of ITO, and the nanosensor was used for the detection of NE. The reduction of NE was observed in two $\mathrm{pH}$ dependent peaks, and the linear dynamic range was found between $100 \mathrm{nM}$ and $25 \mu \mathrm{M}$ with a detection limit of $87 \mathrm{nM}$ [85]. Attempts have also been made to determine DA in human urine using AuNPs-coated poly (3,4ethylene-dioxythiophene) nanosensor using sodium dodecyl sulfate [86]. The DA concentration versus peak current plot showed two linear regions: $0.5-20 \mu \mathrm{ML}^{-1}$ and $25-140 \mu \mathrm{ML}^{-1}$. The method was found highly sensitive and reproducible with good selectivity and long term stability. AuNPs have also been used in the composites for the determination of neurotransmitters. One of such examples is the fabrication of nano-Au/cysteamine/GC sensor for the determination of DA in presence of high concentration of ascorbic acid (AA). The cysteamine was bound at the surface of glassy carbon (GC) using cyclic voltammetry [87]. The oxidation of DA occurred at $0.175 \mathrm{~V}$, and linear dynamic range for the determination was observed between $1.0 \times 10^{-8}$ and $2.5 \times 10^{-5} \mathrm{ML}^{-1}$ with a detection limit of $4 \mathrm{nML}^{-1}$. The method was simple, and satisfactory results were observed. The electrodeposition of AuNPs clusters over insulating overoxidized polypyrrole film modified GC has been used by Guo et al. [88] for the determination of DA and 5-HT in presence of 100-fold concentration of AA in human blood serum. The oxidation peaks of the three compounds were observed at $0.37,0.20$ and $0.01 \mathrm{~V}$ versus SCE for 5-HT, DA, and AA, respectively. The method was sensitive, and a detection limit of $1 \mathrm{nM}$ for $5-\mathrm{HT}$ and $15 \mathrm{nM}$ for DA was observed.

Another important clinical target is tryptophan (2amino-3-(1H-indol-3-yl)-propionic acid, Trp), an important and essential amino acid for humans and herbivores. It is also a potent precursor of several metabolites such as 5-HT, melatonin, and niacin. It is an indispensable ingredient of various types of proteins, therefore, must be added in human nutrition for establishing and maintaining positive balance of nitrogen. A nanosensor based on the electrodeposition of AuNPs onto carbon nanotube film has been used for the amperometric determination of $\operatorname{Trp}$ at the physiological $\mathrm{pH}$ [89]. The linear dynamic range was found between $30 \mathrm{nM}$ and $2.5 \mu \mathrm{M}$, and a detection limit of $10 \mathrm{nM}$ was observed. The method was successfully used to determine tryptophan in pharmaceutical samples. In another attempt, AuNPs attached multiwall carbon nanotubes (MWCNT) on ITO have been used for the determination of Trp [90]. The use of AuNPsdoped MWCNT shifted the peak potential of Trp to $0.669 \mathrm{~V}$ as compared to $0.760 \mathrm{~V}$ in absence of AuNPs, which clearly indicated the high electrocatalytic activity of the fabricated nanosensor. The determination of Trp was carried out in human urine and blood serum using standard addition method, and good reproducibility was observed. AuNPs have also seen their applications in clinical analysis of glucose.

A glucose nanosensor based on AuNPs decorated MWCNT at GC was used by Lim et al. [91]. The sensor was further modified with a layer of glucose oxidase and 
chitosan and used as electrochemiluminescence nanosensor. The sensor showed excellent performance for glucose detection and a wide linear range of $1-1000 \mu \mathrm{M}$ was observed with a detection limit of $0.5 \mu \mathrm{M}$. A colorimetric bioassay for the glucose determination in human serum has been developed using self-assembled AuNPs with a thiol derivatized mannose [92]. The change in simple surface plasmon absorption band resulting from this method provides a selective method to quantify glucose. A linear concentration range of 500-4000 $\mu \mathrm{g} / \mathrm{mL}$ with a detection limit of $363 \mu \mathrm{g} / \mathrm{mL}$ was observed. The practical utility of the method was examined by applying the colorimetric assay for the determination of glucose in human serum samples. The reported method is simple, and results can be achieved in $10 \mathrm{~min}$ and can be applied for the determination of human blood glucose levels without the use of enzymes.

Morphine (MO), a well-known alkaloid, is frequently used to relieve severe pain for patients, especially for those who undergo a surgical procedure. However, when overdosed or abused, MO is toxic and can cause disruption in the central nervous system. Therefore, to prevent overdose-induced toxication, it is necessary to sensitively determine the concentrations of MO in patient's blood or urine. An easy-to-use approach for directly electrodepositing AuNPs onto carbon paste electrode (CPE) to construct AuNPs modified carbon paste electrode (AuNPCPE) is performed [93]. The electrochemistry of $\mathrm{MO}$ is investigated by cyclic voltammetry, differential pulse voltammetry, and electrochemical impedance measurements. The results indicate that this strategy provides a promising approach for highly sensitive morphine sensing that offers an excellent response for morphine in the concentration range of $4.0 \times 10^{-7}-2.0 \times 10^{-4} \mathrm{~mol} \mathrm{~L}^{-1}$, with a detection limit of $4.21 \times 10^{-9} \mathrm{~mol} \mathrm{~L}^{-1}$. AuNPCPE has also been successfully applied to the determination of morphine in urine samples with a low detection limit and satisfactory recovery. The good results indicate that AuNPCPE holds great promise in practical applications. Apart from the direct application of AuNPs in clinical chemistry of electrochemically active compounds, AuNPs have also attracted attention in the immunoassay of proteins and hormones. For example, an enzyme-catalyzed Ag deposition on irregular shaped AuNPs has been used for the electrochemical immunoassay of alpha-fetoprotein [94]. The assay was carried out using a sandwich-type protocol, and a wide dynamic linear range from 0.1 to $200 \mathrm{ng} \mathrm{mL}^{-1}$ was observed. The interesting feature of the nanobiosensor was its disposable nature and acceptable reproducibility, as no significant difference was observed in the analysis of 10 clinical serum samples. An electrochemical assay was also developed by using AuNPspolyaniline-nanogold microspheres (GPGs) for detecting thyroid stimulating hormone [95]. The GPGs were first synthesized and functionalized with horseradish peroxidaseconjugated thyroid-stimulating hormone antibody (HRP$\mathrm{Ab} 2$ ), and then thyroid-stimulating hormone (TSH) was detected. The strong attachment of HRP-Ab2 was observed on GPGs and resulted in good reproducibility, and a detection limit of $0.005 \mu \mathrm{IU} \mathrm{mL}^{-1} \mathrm{TSH}$ was observed. The analysis of 15 spiked serum samples exhibited no significant difference between the developed method and the commercially available enzyme-linked immunosorbent assay (ELISA).

\section{Biosensors Based on AuNPs and Conjugates}

Biosensors are analytical devices that are based on the coupling of an immobilized biologically active compound called a receptor with a signal transducer and an electronic amplifier [96]. After the discovery of nanomaterials, various interdisciplinary strategies have been developed for the sensitive detection of various analytes present in biological and environmental matrix. Among all nanomaterials, Au nanoparticles (AuNPs) have widely been used because of their sizedependent electrical properties, high surface area-to-volume ratios, high electrocatalytic activities, and ease of chemical modification. Various biorecognision elements (antibodies, aptamers, peptides, DNA, etc.) have been attached in various ways to achieve a low detection limits. In this section some of the important fabrications strategies have been discussed based on various types of biorecognision elements.

The general working principle of the immunosensors relying on the specific immunochemical identification of antibodies antigens immobilized on a transducer to antigens in the sample media can produce analytical signals dynamically varying with the concentrations of analytes of interest. In the recent years construction of immunosensors using AuNPs have received significant attention. Numerous immunosensors are developed so far where antibodies are directly attached with the AuNPs. The ability of AuNPs to provide a stable immobilization of biomolecules, biocompatibility, and ease of surface functionalization provides a major advantage of AuNPs in the development of immunosensors. Various approaches like layer by layer selfassembly using nafion [97], dithiothreitol 3, cysteamine [98], 4-aminothiophenol [99], polyvinyl butyral [100] have been used in the fabrication of immunosensors. In one study, a spacer arm antibody was covalently attached onto the AuNPs and applied for the electrochemical immunoassay [101]. AuNPs have also been widely applied for the detection of cancer biomarkers. This study described that AuNPs were efficient in preserving the action and orientation of the antibody, and it can form a key platform in several medical immunodiagnostics. Very recently, inkjet-printed AuNPs arrays coupled with electrochemical detection cancer biomarker interleukin-6 (IL-6) in serum have been developed. Biorecognision antibodies for IL- 6 were linked onto the eight-electrode array and used in sandwich immunoassays. A biotinylated secondary antibody with 16-18 horseradish peroxidase labels was used, and detection was achieved by hydroquinone-mediated amperometry with a clinically applicable detection limit of $20 \mathrm{pg} \mathrm{mL}^{-1}$ [102]. Apart of cancer biomarker detection, strategies using AuNPs have also been developed to understand the cancer immunology. In this regard, a quick and sensitive protocol for the detection of alpha-enolase (ENO1) is developed using an electrochemical sandwich immunosensor. Since ENO1 has been correlated 
with small cell lung cancer, nonsmall cell lung cancer, and head and neck cancer, it has been used as a potential diagnostic marker for lung cancer. The anti-ENO1 monoclonal antibody was adsorb on polyethylene glycol-modified disposable screen-printed electrode as the detection platform. The polyclonal secondary anti-ENO1-tagged AuNPs congregates as electrochemical signal probes. This AuNPs congregatebased assay provided an amplification approach for detecting ENO1 at trace levels, leading to a detection limit as low as $11.9 \mathrm{fg}$ (equivalent to $5 \mathrm{microL}$ of a $2.38 \mathrm{pg} / \mathrm{mL}$ solution [103]. Another example of AuNPs for signal amplification was shown by Zhu et al. [104]. In this case, an amperometric immunosensor with an enhanced sensitivity for the detection of neomycin ( $\mathrm{Neo}$ ) was prepared by covalently immobilizing a monoclonal Neo antibody onto a new nanoconducting surface, as a sensor probe. The probe was used to detect Neo in a sandwich-type approach, where the secondary antibody was attached to AuNPs-decorated multiwall carbon nanotubes labeled with hydrazine. Hydrazine on the conjugate served as a catalyst for the reduction of hydrogen peroxide, and the catalytic current was monitored at $-0.45 \mathrm{~V}$ versus $\mathrm{Ag} / \mathrm{AgCl}$. The performance of the immunosensor with and without AuNPs on the probe and the conjugate was compared. A linear dynamic range for Neo analysis was obtained between $10 \mathrm{ng} / \mathrm{mL}$ and $250 \mathrm{ng} / \mathrm{mL}$ with a detection limit of $6.76 \pm 0.17 \mathrm{ng} / \mathrm{mL}$. In another signal amplification strategy, multifunctionalized AuNPs (MFAuNPs) was developed and applied for the electrochemical impedance immunosensor. The sensor was utilized for the detection of protein A, through the stepwise immobilization of 1, 6-hexanedithiol, AuNPs, and IgG on the Au electrode via self-assembling technique. The interfacial properties of the modified electrodes were evaluated in the presence of $\mathrm{Fe}(\mathrm{CN})_{6}{ }^{4-/ 3-}$ couple redox as a probe by cyclic voltammetry and electrochemical impedance spectroscopy. The electrochemical behavior of the redox probe was affected by the accumulation of treated substances on the electrode surface. It was interesting to note that there is no significant increase in the electron transfer resistance after the binding of protein A to $\operatorname{IgG}$ on the electrode surface without amplification. The changes in the electron transfer resistance on the IgG-modified electrodes became more sensitive after the MFAuNPs were introduced for signal amplification. The increments of amplified impedance showed good correlation of the detection of protein A in the range of $5-1000 \mathrm{pg} / \mathrm{mL}$ with a detection limit of $1 \mathrm{pg} / \mathrm{mL}$. In this strategy, the MFAuNPs were successfully applied for the highly sensitive and selective amplification of biomolecules in the picogram range [105]. Very recently, a new electrochemical detection methodology has been developed describing the practical application and integration of nanoparticle-enhanced detection into electrochemical biosensing technologies [106]. Immunoglobulin E (IgE) was used as a model protein biomarker, which possesses two distinct epitopes for antibody (anti-IgE) and DNA aptamer binding. A surface sandwich assay format was utilized involving the specific adsorption of IgE onto a gold electrode surface that was premodified with a monolayer of aptamernanoparticle conjugates followed by the specific interaction of alkaline phosphatase- (ALP-) conjugated anti-IgE. A femtomolar detection of IgE has been achieved. The signal enhancement associated with the nanoparticle was clearly demonstrated using analytical methods and control experiments. Another focus in recent time is to detect important cardiac biomarker such as troponin-I using AuNPs. In one study, troponin-I has been detected using an immunoassay where a specific monoclonal antibody against troponin-I was modified on the GNP-coated ITO electrode surface by selfassembly and characterized by electrochemical techniques. The immunoreaction was monitored by measuring open circuit potential (OCP). This method was fairly simple and stable. A linear dependence of OCP changes according to troponin-I concentrations is observed in the range of concentration from 1 to $100 \mathrm{ng} / \mathrm{mL}$ [107]. AuNPs have also been used for the evaluation of protein phosphorylation using a simple electrochemical method. This approach of protein phosphorylation is expected to be much simpler and sensitive compared to the conventional methods using mass spectrometry. The method relies on the labeling of a specific phosphorylation event with $\mathrm{Au}$ nanoparticles, followed by electrochemical detection [108]. This study demonstrates the use of AuNPs as electroactive indicators for kinase activity and inhibition has been demonstrated. Furthermore, the electrochemical protein phosphorylation assay will be helpful for the development of cost-effective biosensors for signal transduction studies. Apart from these approaches, the effect of the AuNPs size, ranging from $5 \mathrm{~nm}$ to $80 \mathrm{~nm}$, on the electrochemical response of screen-printed carbon electrodes (SPCEs) used as electrochemical transducers is investigated for the first time recently [109]. To confirm this size effect, a simple hydrodynamic modelling and calculation at the nanoscale level is applied so as to find the effect of the size of AuNPs upon the electrochemical response. The results show that the greatest signal for AuNPs suspension for the same concentration of total $\mathrm{Au}$ is obtained for the $20 \mathrm{~nm}$ sized nanoparticles. The size effect is also studied for AuNPs acting as electroactive labels in an immunosensor that employs magnetic beads as platforms of the bioreactions. The best response for the $5 \mathrm{~nm}$ AuNPs in this case is due to the fact that in the immunosensing conditions the Brownian motions are minimized because the AuNPs contact with the electrotransducer surface is induced by the immunoreaction, and the fast magnetic collection of the nanoparticles used as antibody labels upon application of a magnetic field. These findings can be extended towards the tuning sensor fabrication for other clinical molecule detection [110]. The successful interaction between $\mathrm{Au}$ and SH has been utilized by Shim's laboratory for the development of electropolymerized self-assembled layer on AuNPs for the detection of inducible nitric oxide synthase (i-NOS) in neuronal cell culture [111]. The results show that AuNPencapsulated conductive polymer are good nanostructured materials as biosensor probes and have a potential application in cell biosensors. The self-assembled layer modified electrode was found to have excellent properties in terms of better conductivity and lower charge transfer resistance. The main advantage of this sensor probe is its simplicity compared to the classical immunoassay methods or optical 
detection-based immunosensing systems. This method was also extended for the toxicity analysis of endocrine disruptors through the in vitro monitoring of i-NOS concentrations using an AuNP-encapsulated conductive polymer-modified immunosensor [112].

AuNPS have also been well utilized in the detection of various kinds of cells such as bacteria and cancer cells. For instance, a disposable immunosensor for Salmonella-enterica subsp. enterica serovar Typhimurium LT2 (S) detection using a magneto-immunoassay and AuNPs as label for electrochemical detection is developed [113]. The immunosensor relies on the application of a screen-printed carbon electrode that incorporates a stable magnet underneath. Salmonella containing samples (i.e., skimmed milk) were examined by using anti-Salmonella magnetic beads (MBs-pSAb) as detector and sandwiching afterwards with AuNPs-modified antibodies (sSAb-AuNPs) detected using differential pulse voltammetry with the detection limit of 143 cells $\mathrm{mL}^{-1}$. This AuNPs detection tools together with magnetic field application report a limit of detection lower than the usual commercial method carried out for comparison purposes in skimmed milk samples.

A fast cancer cell detection and quantification method, based on the electrocatalytic properties of AuNPs towards the hydrogen evolution reaction has been reported recently [114]. This method effectively detects the rare circulating tumor cells (CTC) through the epithelial cell adhesion molecule (EpCAM), a $30-40 \mathrm{kDa}$ type I glycosylated membrane protein expressed at low levels in a variety of human epithelial tissues and overexpressed in most solid cancers [115]. The method establishes a selective CTC assay capable of detecting $4 \times 10^{3}$ cancer cells in suspension that can be extended to several other cells detection scenarios. In another study, a novel strategy for the rapid identification and high sensitive detection of different kinds of cancer cells by means of electrochemical and contact angle measurements has been performed. A simple, label-free method based on the functionalized AuNPs-modified interface has been utilized to distinguish the different cancer cells and drug resistant blood cancer cells. The detection limit was $\sim 10^{3}$ cells $\mathrm{mL}^{-1}$ which is highly applicable for clinical applications of cells [116]. Conducting polymer nanofibers-AuNPs nanocomposite has also been applied for the detection of cancer cells. In this regard, polyaniline nanofibers- (PANI-NF-) AuNPs composites were prepared and based on the simple electrostatic reaction between the positive charges on the surface of PANI-NF and the negatively charged AuNPs [117]. This nanocomposite was utilized to develop an electrochemical cytosensor based on the self-assembly of foliate on PANINF/AuNP nanocomposite. This cytosensor was applied for the in vitro detection of cancer cells based on the selective binding between the folate receptor on cancer cell surface and a folate immobilized on PANI-NF/AuNPs nanocomposite. This cytosensor has several advantages, such as easy construction, short response time, high sensitivity, easy regeneration, good stability, and freedom of additional labeling, which can be thus used for a highly sensitive detection of cancer cells.

\section{Conclusions}

AuNPs such fascinating features as ease of synthesis and surface functionalization that are highly biocompatibility, sensitive, and decent optical properties make AuNPs still the most attractive nanomaterial and one of the most studied in the bioanalytical field. AuNPs have emerged as promising nanoplatforms for efficient diagnostics and therapeutics by merging the characteristic properties they possess at the nanometric scale with the practical immobilization of specific ligands on the surface. Therefore, they have become ideal candidates for molecularly sensitive detection, highly efficient contrast agents for molecular imaging, and carriers for targeted drug and gene delivery. Nonetheless, a better fundamental understanding of AuNPs behavior in biological systems needs to be addressed in future, as well as the engineering of novel AuNPs, which can overcome the drawbacks related to currently developed AuNPs. In future AuNPs possessing enhance biodistribution, and enhanced electrical and optical characteristics will provide better way towards clinical diagnostics.

\section{Acknowledgments}

P. Chandra is thankful to Amity Institute of Biotechnology (AIB), Amity University for the AIB research facilities. R. N. Goyal is thankful to Council of Scientific and Industrial Research, New Delhi, and also Korean Federation of Science and Technology, South Korea, for awarding Brain Pool Fellowship. Y. B. Shim is thankful to the support of a 2-Year research Grant of Pusan National University (2011-2012).

\section{References}

[1] C. N. R. Rao, F. L. Deepak, G. Gundiah, and A. Govindaraj, "Inorganic nanowires," Progress in Solid State Chemistry, vol. 31, no. 1-2, pp. 5-147, 2003.

[2] C. Suryanarayana and C. C. Koch, "Nanocrystalline materialscurrent research and future directions," Hyperfine Interactions, vol. 130, no. 1-4, pp. 5-44, 2000.

[3] H. S. Nalwa, Handbook of Nanostructured Materials and Nanotechnology, Elsevier, 2000.

[4] G. M. Gadd, "Metals, minerals and microbes: geomicrobiology and bioremediation," Microbiology, vol. 156, pp. 609-643, 2010.

[5] J. D. Bryan and D. R. Gamelin, "Doped semiconductor nanocrystals: synthesis, characterization, physical properties, and applications," Progress in Inorganic Chemistry, vol. 54, pp. 47-126, 2005.

[6] E. R. Hitzky, K. Ariga, and Y. Lvov, Bio-Inorganic Hybrid Nanomaterials-Strategies, Syntheses, Characterization and Application, Wiley-VCH, 2008.

[7] Y. Yin and A. Alivisatos, "Colloidal nanocrystal synthesis and the organic-inorganic interface," Nature, vol. 437, pp. 664-670, 2005.

[8] C. M. Lieber, "Semiconductor nanowires: a platform for nanoscience and nanotechnology," MRS Bulletin, vol. 36, pp. 1052-1063, 2011.

[9] T. Hillie and M. Hlophe, "Nanotechnology and the challenge of clean water," Nature Nanotechnology, vol. 2, no. 11, pp. 663-664, 2007. 
[10] M. M. Khin, A. S. Nair, V. J. Babu, R. Murugan, and S. Ramakrishna, "A review on nanomaterials for environmental remediation," Energy \& Environmental Science, vol. 5, pp. 80758109, 2012.

[11] P. J. Vikesland and K. R. Wigginton, "Nanomaterial enabled biosensors for pathogen monitoring-a review," Environmental Science \& Technology, vol. 44, pp. 3656-3669, 2010.

[12] A. Rodriguez, "Activation of gold nanoparticles on titania: a

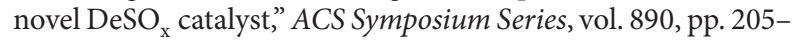
209, 2004.

[13] X. Wang, C. Wang, L. Cheng, S.-T Lee, and Z. Liu, "Noble metal coated single-walled carbon nanotubes for applications in surface enhanced Raman scattering imaging and photothermal therapy," Journal of the American Chemical Society, vol. 134, pp. 7414-7422, 2012.

[14] Y. Su, X. Wei, F. Peng et al., "Gold nanoparticles-decorated silicon nanowires as highly efficient near-infrared hyperthermia agents for cancer cells destruction," Nano Letters, vol. 12, pp. 1845-1850, 2012.

[15] M. Faraday, "Experimental relations of gold (and other metals) to light," Philosophical Transactions of the Royal Society of London, vol. 147, pp. 145-181, 1857.

[16] G. T. Beilby, "The effects of heat and of solvents on thin films of metal," Proceedings of the Royal Society A, vol. 72, pp. 226-235, 1903.

[17] V. V. Mody, R. Siwale, A. Singh, and H. R. Mody, "Introduction to metallic nanoparticles," Journal of Pharmacy and Bioallied Sciences, vol. 2, pp. 282-289, 2010.

[18] D. A. Giljohann, D. S. Seferos, W. L. Daniel, M. D. Massich, P. C. Patel, and C. A. Mirkin, "Gold nanoparticles for biology and medicine," Angewandte Chemie, vol. 49, pp. 3280-3294, 2010.

[19] M. A. Hayat, Colloidal Gold: Principles, Methods, and Applications, Academic Press, San Diego, Calif, USA, 1989.

[20] D. Huang, F. Liao, S. Molesa, D. Redinger, and V. Subramanian, "Plastic-compatible low resistance printable gold nanoparticle conductors for flexible electronics," Journal of the Electrochemical Society, vol. 150, no. 7, pp. G412-G417, 2003.

[21] T. Stuchinskaya, M. Moreno, M. J. Cook, D. R. Edwards, and D. A. Russell, "Targeted photodynamic therapy of breast cancer cells using antibody-phthalocyanine-gold nanoparticle conjugates," Photochemical and Photobiological Sciences, vol. 10, no. 5, pp. 822-831, 2011.

[22] S. D. Brown, P. Nativo, J. A. Smith et al., "Gold nanoparticles for the improved anticancer drug delivery of the active component of oxaliplatin," Journal of the American Chemical Society, vol. 132, no. 13, pp. 4678-4684, 2010.

[23] C. S. S. R. Kumar, Nanomaterials for Biosensors, John Wiley \& Sons, 2007.

[24] K. Saha, S. S. Agasti, C. Kim, X. Li, and V. M. Rotello, "Gold nanoparticles in chemical and biological sensing," Chemical Reviews, vol. 112, pp. 2739-2779, 2012.

[25] S. D. Perrault and W. C. W. Chan, "In vivo assembly of nanoparticle components to improve targeted cancer imaging," Proceedings of the National Academy of Sciences of the United States of America, vol. 107, no. 25, pp. 11194-11199, 2010.

[26] G. Peng, U. Tisch, O. Adams et al., "Diagnosing lung cancer in exhaled breath using gold nanoparticles," Nature Nanotechnology, vol. 4, pp. 669-673, 2009.

[27] D. T. Thompson, "Using gold nanoparticles for catalysis," Nano Today, vol. 2, no. 4, pp. 40-43, 2007.
[28] Z.-J. Zhang, C.-X. Wan, and Y. Wang, "Fluorescent property of gold nanoparticles with different surface structures," Chinese Journal of Chemical Physics, vol. 20, p. 796, 2007.

[29] D. L. Feldheim and C. A. Foss, Metal Nanoparticles: Synthesis, Characterization, and Applications, Marcel Dekker, New York, NY, USA, 2002.

[30] M. C. Daniel and D. Astruc, "Gold nanoparticles: assembly, supramolecular chemistry, quantum-size-related properties, and applications toward biology, catalysis, and nanotechnology," Chemical Reviews, vol. 104, no. 1, pp. 293-346, 2004.

[31] J. A. Dahl, B. L. S. Maddux, and J. E. Hutchison, “Toward greener nanosynthesis," Chemical Reviews, vol. 107, no. 6, pp. 2228-2269, 2007.

[32] S. K. Ghosh and T. Pal, "Interparticle coupling effect on the surface plasmon resonance of gold nanoparticles: from theory to applications," Chemical Reviews, vol. 107, no. 11, pp. 47974862, 2007.

[33] N. L. Rosi and C. A. Mirkin, "Nanostructures in biodiagnostics," Chemical Reviews, vol. 105, no. 4, pp. 1547-1562, 2005.

[34] X. Xu, M. S. Han, and C. A. Mirkin, "A gold-nanoparticle-based real-time colorimetric screening method for endonuclease activity and inhibition," Angewandte Chemie, vol. 46, no. 19, pp. 3468-3470, 2007.

[35] J. S. Lee, P. A. Ulmann, M. S. Han, and C. A. Mirkin, "A DNAgold nanoparticle-based colorimetric competition assay for the detection of cysteine," Nano Letters, vol. 8, no. 2, pp. 529-533, 2008.

[36] P. Podsiadlo, V. A. Sinani, J. H. Bahng, N. W. S. Kam, J. Lee, and N. A. Kotov, "Gold nanoparticles enhance the anti-leukemia action of a 6-mercaptopurine chemotherapeutic agent," Langmuir, vol. 24, pp. 568-574, 2008.

[37] Y. H. Chen, C. Y. Tsai, P. Y. Huang et al., "Methotrexate conjugated to gold nanoparticles inhibits tumor growth in a syngeneic lung tumor model," Molecular Pharmaceutics, vol. 4, no. 5, pp. 713-722, 2007.

[38] G. F. Paciotti, L. Myer, D. Weinreich et al., "Colloidal gold: a novel nanoparticle vector for tumor directed drug delivery," Drug Delivery, vol. 11, no. 3, pp. 169-183, 2004.

[39] D. J. Javier, N. Nitin, M. Levy, A. Ellington, and R. RichardsKortum, "Aptamer-targeted gold nanoparticles as molecularspecific contrast agents for reflectance imaging," Bioconjugate Chemistry, vol. 19, no. 6, pp. 1309-1312, 2008.

[40] J. Aaron, N. Nitin, K. Travis et al., "Plasmon resonance coupling of metal nanoparticles for molecular imaging of carcinogenesis in vivo," Journal of Biomedical Optics, vol. 12, no. 3, Article ID 034007, 2007.

[41] S. Lee, E. J. Cha, K. Park et al., "A near-infrared-fluorescencequenched gold-nanoparticle imaging probe for in vivo drug screening and protease activity determination," Angewandte Chemie, vol. 47, no. 15, pp. 2804-2807, 2008.

[42] I. H. El-Sayed, X. Huang, and M. A. El-Sayed, "Surface plasmon resonance scattering and absorption of anti-EGFR antibody conjugated gold nanoparticles in cancer diagnostics: applications in oral cancer," Nano Letters, vol. 5, no. 5, pp. 829-834, 2005.

[43] G. von Maltzahn, J.-H. Park, A. Agrawal et al., "Computationally guided photothermal tumor therapy using long-circulating gold nanorod antennas," Cancer Research, vol. 69, no. 9, pp. 3892-3900, 2009.

[44] Y. Cheng, A. C. Samia, J. D. Meyers, I. Panagopoulos, B. Fei, and C. Burda, "Highly efficient drug delivery with gold nanoparticle 
vectors for in vivo photodynamic therapy of cancer," Journal of the American Chemical Society, vol. 130, no. 32, pp. 10643-10647, 2008.

[45] F. Kim, J. H. Song, and P. Yang, "Photochemical synthesis of gold nanorods," Journal of American Chemical Society, vol. 124, pp. 14316-14317, 2002.

[46] Y. Sun and Y. Xia, "Mechanistic study on the replacement reaction between silver nanostructures and chloroauric acid in aqueous medium," Journal of the American Chemical Society, vol. 126, no. 12, pp. 3892-3901, 2004.

[47] S. H. Yu, H. Cölfen, and Y. Mastai, "Formation and optical properties of gold nanoparticles synthesized in the presence of double-hydrophilic block copolymers," Journal of Nanoscience and Nanotechnology, vol. 4, no. 3, pp. 291-298, 2004.

[48] T. Sakai and P. Alexandridis, "Single-step synthesis and stabilization of metal nanoparticles in aqueous pluronic block copolymer solutions at ambient temperature," Langmuir, vol. 20, no. 20, pp. 8426-8430, 2004.

[49] X. Sun, S. Dong, and E. Wang, "One-step polyelectrolytebased route to well-dispersed gold nanoparticles: synthesis and insight," Materials Chemistry and Physics, vol. 96, no. 1, pp. 2933, 2006.

[50] W. Chen, W. P. Cai, C. H. Liang, and L. D. Zhang, "Synthesis of gold nanoparticles dispersed within pores of mesoporous silica induced by ultrasonic irradiation and its characterization," Materials Research Bulletin, vol. 36, no. 1-2, pp. 335-342, 2001.

[51] A. Housni, M. Ahmed, S. Liu, and R. Narain, "Monodisperse protein stabilized gold nanoparticles via a simple photochemical process," Journal of Physical Chemistry C, vol. 112, no. 32, pp. 12282-12290, 2008.

[52] K. L. McGilvray, M. R. Decan, D. Wang, and J. C. Scaiano, "Facile photochemical synthesis of unprotected aqueous gold nanoparticles," Journal of the American Chemical Society, vol. 128, no. 50, pp. 15980-15981, 2006.

[53] S. Meltzer, R. Resch, B. E. Koel et al., "Fabrication of nanostructures by hydroxylamine seeding of gold nanoparticle templates," Langmuir, vol. 17, no. 5, pp. 1713-1718, 2001.

[54] K. Mallick, Z. L. Wang, and T. Pal, "Seed-mediated successive growth of gold particles accomplished by UV irradiation: a photochemical approach for size-controlled synthesis," Journal of Photochemistry and Photobiology A, vol. 140, no. 1, pp. 75-80, 2001.

[55] V. G. Pol, A. Gedanken, and J. Calderro-Moreno, "Deposition of gold nanoparticles on silica spheres: a sonochemical approach," Chemistry of Materials, vol. 15, pp. 1111-1123, 2003.

[56] A. Dawson and P. V. Kamat, "Complexation of gold nanoparticles with radiolytically generated thiocyanate radicals $\left((\mathrm{SCN})_{2}^{--}\right)$," Journal of Physical Chemistry B, vol. 104, no. 50, pp. 11842-11846, 2000.

[57] E. Gachard, H. Remita, J. Khatouri, B. Keita, L. Nadjo, and J. Belloni, "Radiation-induced and chemical formation of gold clusters," New Journal of Chemistry, vol. 22, no. 11, pp. 1257-1265, 1998.

[58] F. Mafune and T. Kondow, "Formation of small gold clusters in solution by laser excitation of interband transition," Chemical Physics Letters, vol. 372, pp. 199-204, 2003.

[59] T. Ishii, H. Otsuka, K. Kataoka, and Y. Nagasaki, "Preparation of functionally PEGylated gold nanoparticles with narrow distribution through autoreduction of auric cation by $\alpha$ Biotinyl-PEG-block-[poly(2-(N,N-dimethylamino)ethyl methacrylate)]," Langmuir, vol. 20, no. 3, pp. 561-564, 2004.
[60] N. R. Jana, L. Gearheart, and C. J. Murphy, "Seeding growth for size control of 5-40 nm diameter gold nanoparticles," Langmuir, vol. 17, no. 22, pp. 6782-6786, 2001.

[61] Y. Xiao, B. Shlyahovsky, I. Popov, V. Pavlov, and I. Willner, "Shape and color of Au nanoparticles follow biocatalytic processes," Langmuir, vol. 21, no. 13, pp. 5659-5662, 2005.

[62] H. I. Schlesinger, H. C. Brown, A. E. Finholt, J. R. Gilbreath, H. R. Hoekstra, and E. K. Hyde, "Sodium borohydride, its hydrolysis and its use as a reducing agent and in the generation of hydrogen," Journal of the American Chemical Society, vol. 75, no. 1, pp. 215-219, 1953.

[63] H. C. Brown and C. A. Brown, "New, Highly active metal catalysts for the hydrolysis of borohydride," Journal of American Chemical Society, vol. 84, pp. 1493-1494, 1962.

[64] P. R. Selvakannan, S. Mandal, R. Pasricha, S. D. Adyanthaya, and M. Sastry, "One-step synthesis of hydrophobized gold nanoparticles of controllable size by the reduction of aqueous chloroaurate ions by hexadecylaniline at the liquid-liquid interface," Chemical Communications, no. 13, pp. 1334-1335, 2002.

[65] S. Chen, K. Huang, and J. A. Stearns, "Alkanethiolate-protected palladium nanoparticles," Chemistry of Materials, vol. 12, pp. 540-547, 2000.

[66] J. Turkevich, P. C. Stevenson, and J. Hillier, "The formation of colloidal gold," Journal of Physical Chemistry, vol. 57, pp. 670673, 1953.

[67] G. Frens, "Controlled nucleation for the regulation of the particle size in monodisperse gold suspensions," Nature, vol. 241, pp. 20-22, 1973.

[68] N. R. Jana, L. Gearheart, and C. J. Murphy, "Evidence for seedmediated nucleation in the chemical reduction of gold salts to gold nanoparticles," Chemistry of Materials, vol. 13, no. 7, pp. 2313-2322, 2001.

[69] G. Carrot, J. C. Valmalette, C. J. G. Plummer et al., "Gold nanoparticle synthesis in graft copolymer micelles," Colloid and Polymer Science, vol. 276, no. 10, pp. 853-859, 1998.

[70] D. Mandal, M. E. Bolander, D. Mukhopadhyay, G. Sarkar, and P. Mukherjee, "The use of microorganisms for the formation of metal nanoparticles and their application," Applied Microbiology and Biotechnology, vol. 69, no. 5, pp. 485-492, 2006.

[71] R. Bali and A. T. Harris, "Biogenic synthesis of Au nanoparticles using vascular plants," Industrial and Engineering Chemical Research, vol. 49, pp. 12762-12772, 2010.

[72] Y. Hao, Y. Chong, S. Li, and H. Yang, "Controlled synthesis of Au nanoparticles in the nanocages of SBA-16: improved activity and enhanced recyclability for the oxidative esterification of alcohols," Journal of Physical Chemistry C, vol. 116, pp. 65126519, 2012.

[73] H. A. Keul, M. Moeller, and M. R. Bockstaller, "Effect of solvent isotopic replacement on the structure evolution of gold nanorods," Journal of Physical Chemistry C, vol. 112, no. 35, pp. 13483-13487, 2008.

[74] J. Liu, M. Anand, and C. B. Roberts, "Synthesis and extraction of $\beta$-D-glucose-stabilized au nanoparticles processed into lowdefect, wide-area thin films and ordered arrays using $\mathrm{CO}_{2}$ expanded liquids," Langmuir, vol. 22, no. 9, pp. 3964-3971, 2006.

[75] M. Larguinho and P. V. Baptisa, "Gold and silver nano particles for clinical diagnostics - from genomics and proteomics," Journal of Proteomics, vol. 75, pp. 2811-2823, 2012.

[76] P. D’Orazio, "Biosensors in clinical chemistry-2011 update," Clinica Chimica Acta, vol. 412, pp. 1749-1761, 2011. 
[77] P. Chandra, H. B. Noh, M. S. Won, and Y. B. Shim, "Detection of daunomycin using phosphatidylserine and aptamer co-immobilized on Au nanoparticles deposited conducting polymer," Biosensors and Bioelectronics, vol. 26, no. 11, pp. 44424449, 2011.

[78] M. Kambayashi, J. Zhang, and M. Oyama, "Crystal growth of gold nanoparticles on indium tin oxides in the absence and presence of 3-mercaptopropyl-trimethoxysilane," Crystal Growth and Design, vol. 5, no. 1, pp. 81-84, 2005.

[79] A. A. Umar and M. Oyama, "Formation of gold nanoplates on indium tin oxide surface: two-dimensional crystal growth from gold nanoseed particles in the presence of poly(vinylpyrrolidone)," Crystal Growth and Design, vol. 6, no. 4, pp. 818-821, 2006.

[80] R. N. Goyal, A. Aliumar, and M. Oyama, "Comparison of spherical nanogold particles and nanogold plates for the oxidation of dopamine and ascorbic acid," Journal of Electroanalytical Chemistry, vol. 631, no. 1-2, pp. 58-61, 2009.

[81] F. K. Alanazi, A. A. Radwan, and A. A. Alsarra, "Biopharmaceutical applications of nanogold," Saudi Pharmaceutical Journal, vol. 18, pp. 179-193, 2010.

[82] G. Lai, L. Wang, J. Wu, H. Ju, and F. Yan, "Electrochemical stripping analysis of nanogold label-induced silver deposition for ultrasensitive multiplexed detection of tumor markers," Analytica Chimica Acta, vol. 721, pp. 1-6, 2012.

[83] R. N. Goyal, V. K. Gupta, M. Oyama, and N. Bachheti, “Gold nanoparticles modified indium tin oxide electrode for the simultaneous determination of dopamine and serotonin: application in pharmaceutical formulations and biological fluids," Talanta, vol. 72, no. 3, pp. 976-983, 2007.

[84] R. N. Goyal, M. A. Aziz, M. Oyama, S. Chatterjee, and A. R. S. Rana, "Nanogold based electrochemical sensor for determination of norepinephrine in biological fluids," Sensors and Actuators B, vol. 153, no. 1, pp. 232-238, 2011.

[85] N. F. Atta, A. Galal, and E. H. El-Ads, "Gold nanoparticlescoated poly(3,4-ethylene-dioxythiophene) for the selective determination of sub-nano concentrations of dopamine in presence of sodiumdodecyl sulfate," Electrochimica Acta, vol. 69, pp. 102-111, 2012.

[86] G. Z. Hu, D. P. Zhang, W. L. Wu, and Z. S. Yang, "Selective determination of dopamine in the presence of high concentration of ascorbic acid using nano-Au self-assembly glassy carbon electrode," Colloids and Surfaces B, vol. 62, no. 2, pp. 199-205, 2008.

[87] J. Li and X. Lin, "Simultaneous determination of dopamine and serotonin on gold nanocluster/overoxidized-polypyrrole composite modified glassy carbon electrode," Sensors and Actuators $B$, vol. 124, no. 2, pp. 486-493, 2007.

[88] Y. Guo, S. Guo, Y. Fang, and S. Dong, "Gold nanoparticle/carbon nanotube hybrids as an enhanced material for sensitive amperometric determination of tryptophan," Electrochimica Acta, vol. 55, no. 12, pp. 3927-3931, 2010.

[89] R. N. Goyal, S. Bishnoi, H. Chasta, A. Md. Aziz, and M. Oyama, "Effect of surface modification of indium tin oxide by nanoparticles on the electrochemical determination of tryptophan," Talanta, vol. 85, pp. 2626-2631, 2011.

[90] B. Haghighi, S. Bozorgzadeh, and L. Gorton, "Fabrication of a novel electrochemiluminescence glucose biosensor using $\mathrm{Au}$ nanoparticles decorated multiwalled carbon nanotubes," Sensors and Actuators B, vol. 155, no. 2, pp. 577-583, 2011.
[91] K. R. Lim, J.-M. Park, H. N. Choi, and W.-Y. Lee, "Gold glyconanoparticle-based colorimetric bioassay for the determination of glucose in human serum," Microchemical Journal, vol. 106, pp. 154-159, 2013.

[92] W. O. Ho, S. Krause, C. J. McNeil et al., "Electrochemical sensor for measurement of urea and creatinine in serum based on ac impedance measurement of enzyme-catalyzed polymer transformation," Analytical Chemistry, vol. 71, no. 10, pp. 19401946, 1999.

[93] W. Lai, D. Tang, X. Que, J. Zhuang, L. Fu, and G. Chen, "Enzyme-catalyzed silver deposition on irregular-shaped gold nanoparticles for electrochemical immunoassay of alphafetoprotein," Analytica Chimica Acta, vol. 755, pp. 62-68, 2012.

[94] Y. Cui, H. Chen, L. Hou et al., "Nanogold-polyaniline-nanogold microspheres-functionalized molecular tags for sensitive electrochemical immunoassay of thyroid-stimulating hormone," Analytica Chimica Acta, vol. 738, pp. 76-84, 2012.

[95] A. P. F. Turner, I. Karube, and G. S. Wilson, Biosensors: Fundamentals and Applications, Oxford University Press, New York, NY, USA, 1987.

[96] D. P. Tang, R. Yuan, Y. Q. Chai et al., "Novel potentiometric immunosensor for hepatitis B surface antigen using a gold nanoparticle-based biomolecular immobilization method," Analytical Biochemistry, vol. 333, no. 2, pp. 345-350, 2004.

[97] M. P. Chatrathi, J. Wang, and G. E. Collins, "Sandwich electrochemical immunoassay for the detection of Staphylococcal enterotoxin B based on immobilized thiolated antibodies," Biosensors and Bioelectronics, vol. 22, no. 12, pp. 2932-2938, 2007.

[98] M. Wang, L. Wang, H. Yuan et al., "Immunosensors based on layer-by-layer self-assembled Au colloidal electrode for the electrochemical detection of antigen," Electroanalysis, vol. 16, no. 9, pp. 757-764, 2004.

[99] M. Wang, L. Wang, H. Yuan et al., "Application of impedance spectroscopy for monitoring colloid Au-enhanced antibody immobilization and antibody-antigen reactions," Biosensors and Bioelectronics, vol. 19, pp. 575-582, 2004.

[100] D. Tang, R. Yuan, Y. Chai, J. Dai, X. Zhong, and Y. Liu, "A novel immunosensor based on immobilization of hepatitis B surface antibody on platinum electrode modified colloidal gold and polyvinyl butyral as matrices via electrochemical impedance spectroscopy," Bioelectrochemistry, vol. 65, no. 1, pp. 15-22, 2004.

[101] G. K. Ahirwal and C. K. Mitra, "Gold nanoparticles based sandwich electrochemical immunosensor," Biosensors and Bioelectronics, vol. 25, no. 9, pp. 2016-2020, 2010.

[102] G. C. Jensen, C. E. Krause, G. A. Sotzing, and J. F. Rusling, "Inkjet-printed gold nanoparticle electrochemical arrays on plastic. Application to immunodetection of a cancer biomarker protein," Physical Chemistry Chemical Physics, vol. 13, pp. 48884894, 2011.

[103] J. A. Ho, H. C. Chang, N. Y. Shih et al., "Diagnostic detection of human lung cancer-associated antigen using a gold nanoparticle-based electrochemical immunosensor," Analytical Chemistry, vol. 82, pp. 5944-5950, 2010.

[104] Y. Zhu, J. I. Son, and Y. B. Shim, "Amplification strategy based on gold nanoparticle-decorated carbon nanotubes for neomycin immunosensors," Biosensors and Bioelectronics, vol. 26, no. 3, pp. 1002-1008, 2010.

[105] C.-C. Lin, L.-C. Chen, C.-H. Huang, S.-J. Ding, C.-C. Chang, and H.-C. Chang, "Development of the multi-functionalized 
gold nanoparticles with electrochemical-based immunoassay for protein A detection," Journal of Electroanalytical Chemistry, vol. 619, pp. 39-45, 2008.

[106] E. J. Nam, E. J. Kim, A. W. Wark, S. Rho, H. Kim, and H. J. Lee, "Highly sensitive electrochemical detection of proteins using aptamer-coated gold nanoparticles and surface enzyme reactions," Analyst, vol. 137, pp. 2011-2016, 2012.

[107] A. J. Saleh Ahammad, Y. H. Choi, K. Koh, J. H. Kim, J. J. Lee, and M. Lee, "Electrochemical detection of cardiac biomarker troponin I at gold nanoparticle-modified ITO electrode by using open circuit potential," International Journal of Electrochemical Science, vol. 6, no. 6, pp. 1906-1916, 2011.

[108] K. Kerman, M. Chikae, S. Yamamura, and E. Tamiya, "Gold nanoparticle-based electrochemical detection of protein phosphorylation," Analytica Chimica Acta, vol. 588, no. 1, pp. 26-33, 2007.

[109] A. de la Escosura-Muñiz, C. Parolo, F. Maran, and A. Mekoçi, "Size-dependent direct electrochemical detection of gold nanoparticles: application in magnetoimmunoassays," Nanoscale, vol. 3, pp. 3350-3356, 2011.

[110] E. Vasilyeva, B. Lam, Z. Fang, M. D. Minden, E. H. Sargent, and S. O. Kelley, "Direct genetic analysis of ten cancer cells: tuning sensor structure and molecular probe design for efficient mRNA capture," Angewandte Chemie, vol. 50, pp. 4137-4141, 2011.

[111] W. Choon, A. Koh, P. Chandra, D.-M. Kim, and Y.-B. Shim, "Electropolymerized self-assembled layer on gold nanoparticles: detection of inducible nitric oxide synthase in neuronal cell culture," Analytical Chemistry, vol. 83, pp. 6177-6183, 2011.

[112] P. Chandra, W. C. Koh, H.-B. Noh, and Y.-B. Shim, "In vitro monitoring of i-NOS concentrations with an immunosensor: the inhibitory effect of endocrine disruptors on i-NOS release," Biosensors and Bioelectronics, vol. 32, pp. 278-282, 2012.

[113] A. S. Afonso, B. Pérez-Lo’pez, R. C. Faria et al., "Electrochemical detection of Salmonella using gold nanoparticles," Biosensors and Bioelectronics, vol. 40, pp. 121-126, 2013.

[114] M. Maltez-da Costa, A. de la Escosura-Muñiz, C. Nogués, L. Barrios, E. Ibáñez, and A. Merkoçi, "Detection of circulating cancer cells using electrocatalytic gold nanoparticles," Small, vol. 8, no. 23, pp. 3605-3612.

[115] P. T. Went, A. Lugli, S. Meier et al., "Frequent EpCam protein expression in human carcinomas," Human Pathology, vol. 35, no. 1, pp. 122-128, 2004.

[116] F. He, Q. Shen, H. Jiang et al., "Rapid identification and high sensitive detection of cancer cells on the gold nanoparticle interface by combined contact angle and electrochemical measurements," Talanta, vol. 77, pp. 1009-1014, 2009.

[117] W. Hui, W. Tian, Y. Yan-Xia et al., "Construction of an electrochemical cytosensor based on polyaniline nanofiber/gold nanoparticle interface and application to detection of cancer cells," Chinese Journal of Analytical Chemistry, vol. 40, pp. 184190, 2012. 

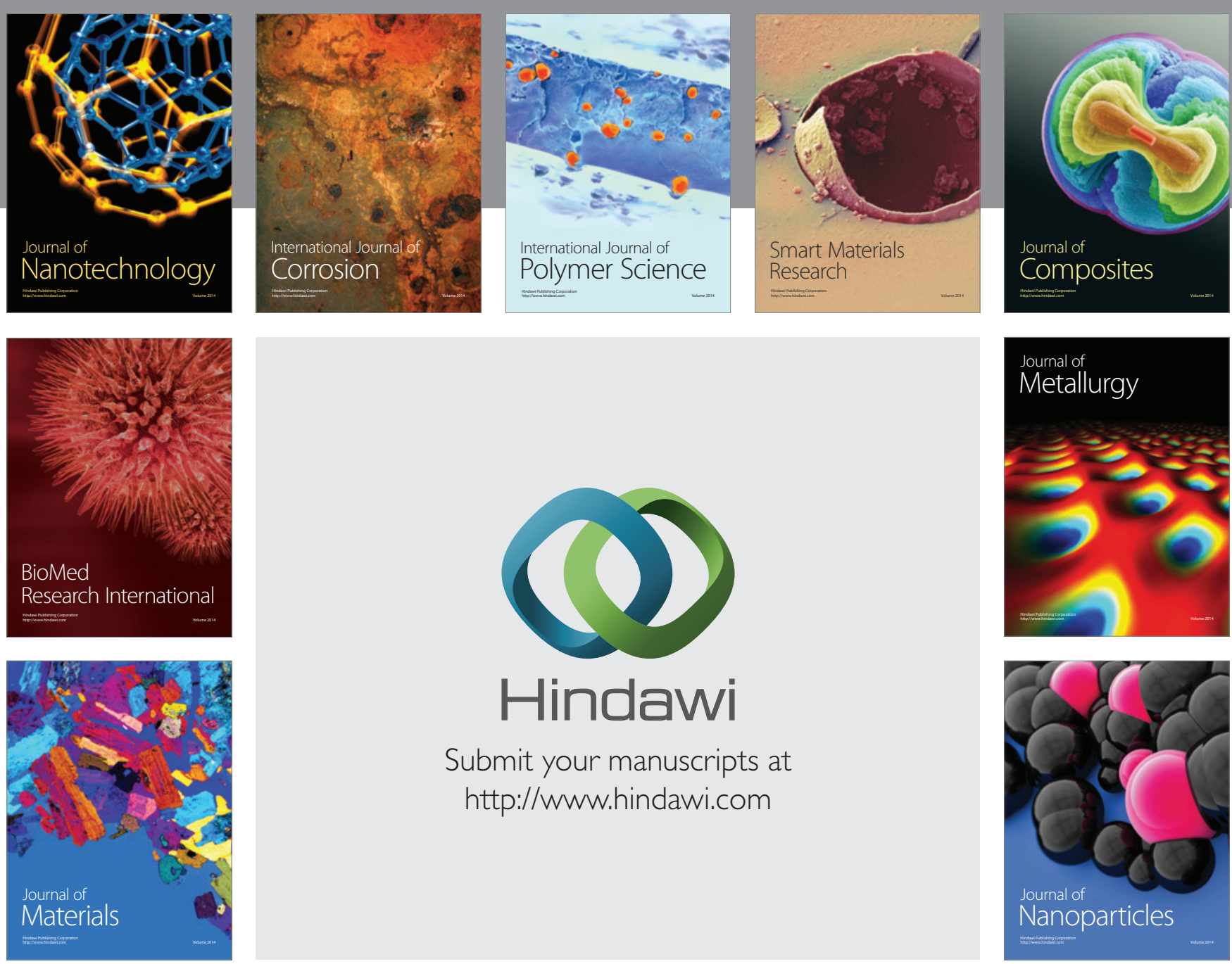

Submit your manuscripts at http://www.hindawi.com
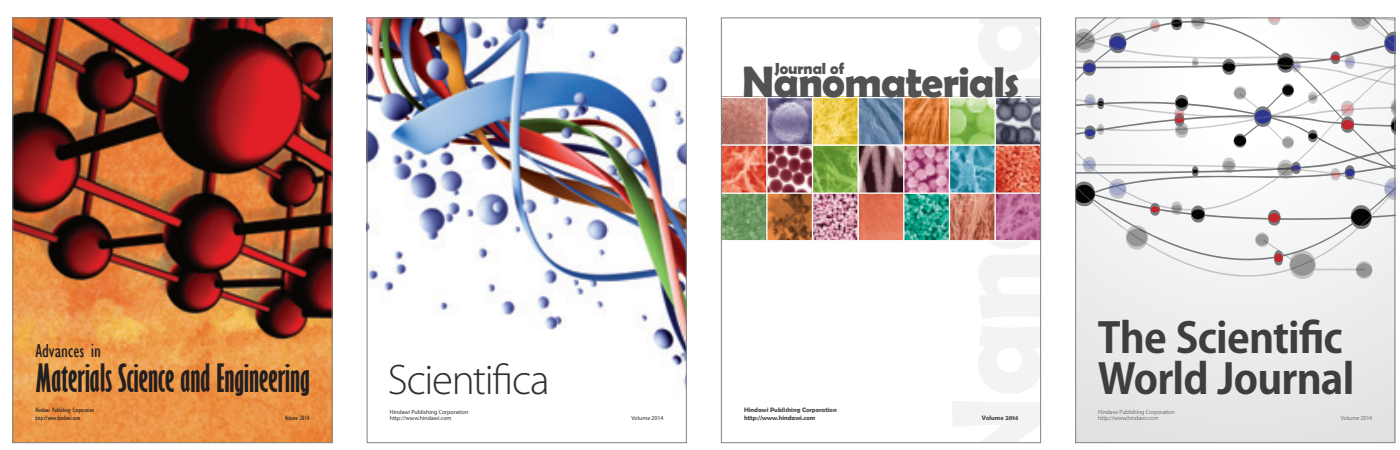

\section{The Scientific World Journal}
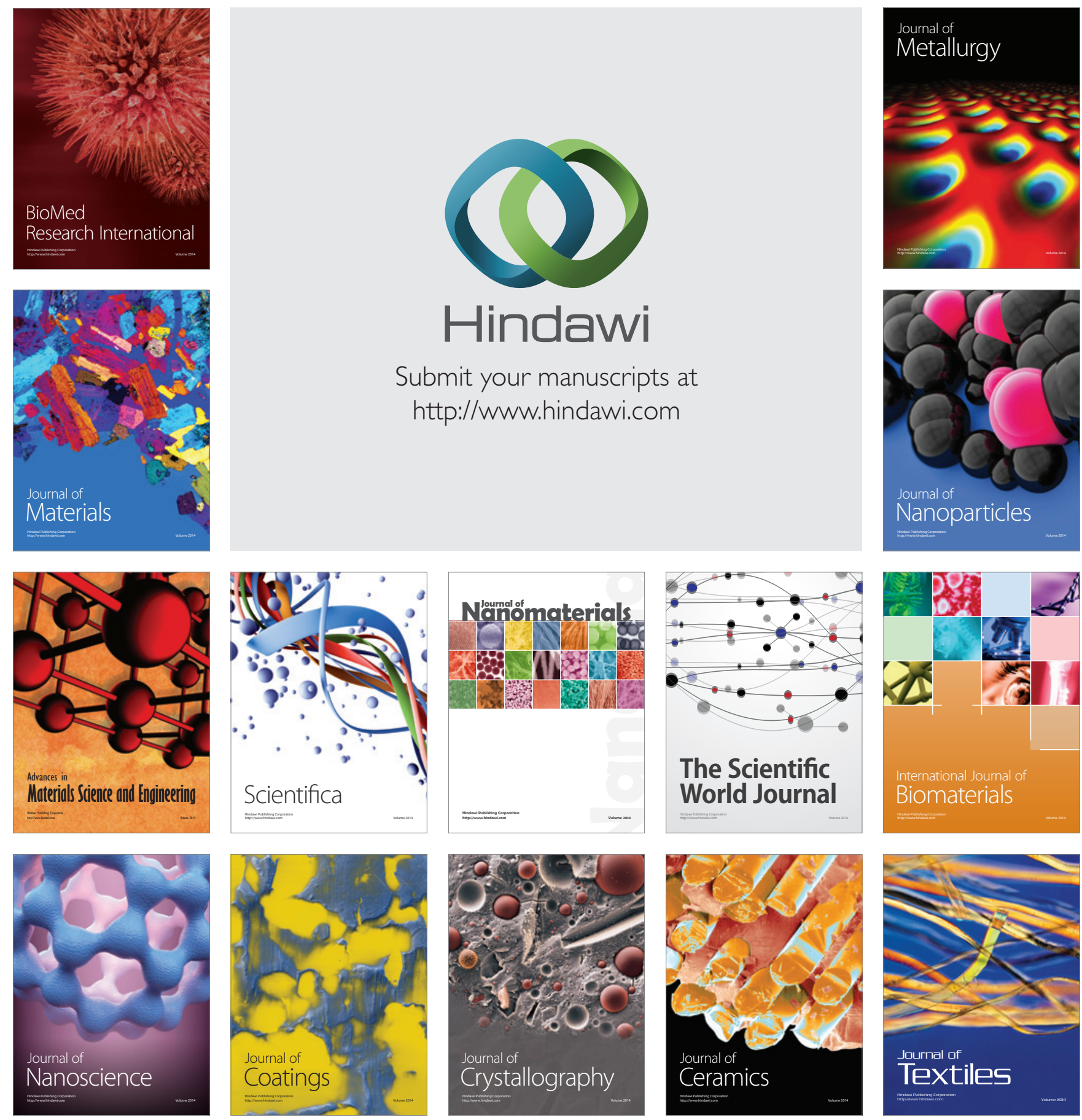